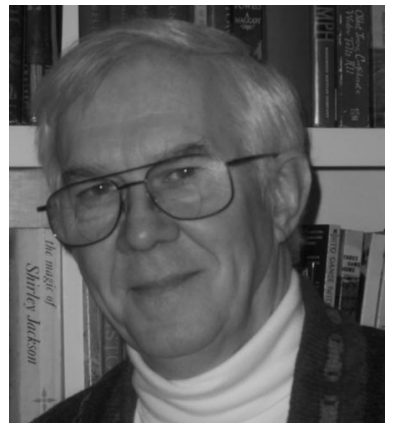

\section{3 in Review}

If it's February, then it's time to review the state of the journal. When I looked at the end-of-year statistics last year, I thought that the journal output might be experiencing some periodic fluctuations. But this past year has shown that if there is a period, it is going to be greater than the two-year duration I had suspected. After a large drop in journal pages four years ago, the number of pages and papers had bounced back strongly in 2000 and then the paper count dropped again in 2001. But for the past two years the number of papers published has increased substantially (see Table 1).

To some degree, the number and size of the special sections have a major effect on the size of the fluctuations. Because each special section is treated in much the same way as an SPIE conference, the response to the call for papers for a special section is very much dependent on the choice of topics, the activity in the field, and the persuasiveness of the editors of the special section. As can be seen in Table 2, the number of special section papers published this year represents only $8 \%$ of the papers in the journal. This is down from $14.5 \%$ last year. However, that will surely change because starting in May we have special sections scheduled every month for the rest of the year. A number of these highlight fields of optical engineering (solid state lighting, illumination design, volume holographic optical elements, optics and photonics for homeland security, diffractive optics, fusion laser engineering, applications of laser ablation and micromachining in optics) that have not had much exposure in this journal. It should be an exciting year. As always, proposals for such special sections are welcomed.

The number of regular papers and $O E$ Letters received increased by $22 \%$ (Table 2) this year. Following an increase of $17 \%$ from last year, Optical Engineering has become a journal that authors use as a forum for information in their field. We appreciate the confidence they have shown by submitting to $O E$. However, if you look at the acceptance rate for papers published last year (Table 3), you will see that it has dropped to $57 \%$. This indicates that the increased number of submissions includes a fair number of papers that are not up to the quality we require for this journal. As I assign the submitted papers to be handled by the Associate Editors, I am struck by the modest results that are reported by some of these papers. In the coming year the editors will be studying whether some papers, although correct, should be published.

This has been the third year of OE Letters. As can be seen in Table 4, the number of papers published and the number of submissions continue to increase dramatically. Our standards for rapid publication have remained high because only one-third of the papers that are submitted are published.

Where are do our papers come from? I have included the data for the past five years in Table 5, which gives the geographical distribution of first authors. Over $93 \%$ of the papers come from three regions: Asia, North America, and Western Europe. The number of papers from Western Europe has been constant for the past four years. For some reason, there was a substantial drop in submissions from North America in 2001. While it has finally rebounded to 2000 levels, the number of papers from Asia has increased from year to year over the same period with a dramatic annual increase of $37 \%$ this past year. This trend of increasing submissions from Asia has been seen by other journals, too.

The increased activity did affect our review perfor-

Table 1 Major statistics for 2000-2003 and percentage changes from 2002.

\begin{tabular}{lrrrrr}
\hline \hline & 2000 & 2001 & 2002 & 2003 & 2003 vs 2002 \\
\hline Number of journal pages & 3360 & 2924 & 3360 & 3672 & $+9.3 \%$ \\
Number of technical pages & 3220 & 2776 & 3210 & 3514 & $+9.5 \%$ \\
Number of papers published & 412 & 385 & 420 & 487 & $+16.0 \%$ \\
\hline \hline
\end{tabular}


Table 2 Regular vs special section papers for 2001-2003 and percentage changes from 2002.

\begin{tabular}{lrrrrrc}
\hline \hline & 2001 & 2002 & $\begin{array}{c}2002 \\
\text { ratio }\end{array}$ & 2003 & $\begin{array}{c}2003 \\
\text { ratio }\end{array}$ & 2003 vs 2002 \\
\hline Regular papers published & 319 & 359 & $85.5 \%$ & 448 & $92.0 \%$ & $+24.8 \%$ \\
Special papers published & 66 & 61 & $14.5 \%$ & 39 & $8.0 \%$ & $-36.1 \%$ \\
Regular papers received & 549 & 643 & & 781 & & $+21.5 \%$ \\
Special papers received & 73 & 44 & & 68 & & $+54.5 \%$ \\
\hline \hline
\end{tabular}

Table 3 Outcomes of papers acted on from 2001 to 2003 (regular papers only; OE Letters not included).

\begin{tabular}{lrrrrrr}
\hline \hline & \multicolumn{2}{c}{2001} & \multicolumn{2}{c}{2002} & \multicolumn{2}{c}{2003} \\
\hline Accepted & 317 & $60.04 \%$ & 445 & $65.35 \%$ & 332 & $57.05 \%$ \\
Declined & 146 & $27.65 \%$ & 173 & $25.40 \%$ & 184 & $31.62 \%$ \\
Closed & 57 & $10.80 \%$ & 51 & $7.49 \%$ & 45 & $7.73 \%$ \\
Withdrawn & 4 & $0.76 \%$ & 4 & $0.59 \%$ & 2 & $0.34 \%$ \\
Transferred & 4 & $0.76 \%$ & 8 & $1.17 \%$ & 19 & $3.26 \%$ \\
Total & $\mathbf{5 2 8}$ & $\mathbf{1 0 0 \%}$ & $\mathbf{6 8 1}$ & $\mathbf{1 0 0 \%}$ & $\mathbf{5 8 2}$ & $\mathbf{1 0 0 \%}$ \\
\hline \hline
\end{tabular}

Table 4 OE Letters statistics for 2001 through 2003.

\begin{tabular}{lccrc}
\hline \hline & 2001 & 2002 & 2003 & $\%$ \\
\hline Letters published & 20 & 27 & 36 & \\
Letters received & 61 & 80 & 124 & \\
Accepted & 25 & 26 & 39 & $33.62 \%$ \\
Declined & 50 & 48 & 77 & $66.38 \%$ \\
\hline \hline
\end{tabular}

Table 5 Number of papers published by region of first author in 1999 through 2003.

\begin{tabular}{lrrrrr}
\hline \hline Region & 1999 & 2000 & 2001 & 2002 & 2003 \\
\hline Africa & 0 & 3 & 2 & 1 & 0 \\
Asia & 77 & 119 & 145 & 154 & 211 \\
Australia & 8 & 7 & 2 & 8 & 8 \\
Eastern Europe & 13 & 19 & 14 & 17 & 7 \\
Middle East & 10 & 18 & 14 & 14 & 15 \\
North America & 108 & 163 & 121 & 139 & 161 \\
South/Central America & 6 & 4 & 8 & 7 & 3 \\
Western Europe & 51 & 79 & 79 & 80 & 82 \\
\hline \hline
\end{tabular}

Table 6 Activity of the editorial office in 2003 (regular papers only, including OE Letters).

\begin{tabular}{lrr}
\hline \hline & \multicolumn{2}{c}{$\%$ change } \\
& Number & vs 2002 \\
\hline Reviewers selected & 2777 & +10.11 \\
Reviews received & 1155 & +1.05 \\
Revised manuscripts received & 402 & -15.90 \\
Papers returned to authors for revision & 440 & -12.35 \\
Communication papers received & 3 & +50.00 \\
OE Letters received & 124 & +55.00 \\
\hline \hline
\end{tabular}

mance somewhat. Table 6 provides an overview of the activity within the journals office for Optical Engineering. After last year's dramatic decrease in the average initial review time from 15.2 weeks to 8.9 weeks for $O E$ and from 5.9 weeks to 3.6 weeks for $O E$ Letters in 2001, it has been reversed by small increases to 8.4 weeks and 4.4 weeks, respectively. Considering the increase in submissions this is still exceptional for research journals. Part of this is due to the nearly total use of electronic submissions. The percentage of electronic submissions has grown from $20 \%$ starting in the spring of 1999 to $50 \%$ in $2000,67 \%$ in $2001,81.4 \%$ last year, and $93.8 \%$ this year. This means that this year, out of a total of 781 papers, only 48 were mailed to SPIE.

Our production time, the time between acceptance and publication, also decreased to 5.8 months for $O E$ papers, but increased slightly to 3.2 months for OE Letters. The SPIE journals staff provides exceptional professional service. Beyond processing all of the papers for the journal, they keep track of errant papers, reviewers, and editors. We owe them our deepest thanks.

A great deal of the work on this journal is done by the many reviewers who evaluate the submissions. While some may write some dismissive one-paragraph reviews, there are many who take the time to write insightful reviews that improve the papers and, on occasion, alert us to cases of plagiarism. To those reviewers, the optical engineering community is in your debt.

The determination of reviewers and rendering of decisions on these papers is the task of the Board of Editors, a very smart group of people with not a lot of time, but a strong sense of service. I am grateful for all the help they provide in publishing Optical Engineering. Their names and affiliations are listed on the masthead of this journal.

With the creation of the Journal of Microlithography, Microfabrication, and Microsystems, known to everyone as $\mathrm{JM}^{3}$, Burn Lin left the board to become its Editor. I thank him for allowing me to give him some on-the-job training. I must thank Angus MacLeod, who was a member of the original board, for his assistance over these six years. Peter Martin from Battelle Northwest will be taking over for him. Touradj Ebrahimi has stepped down after several years of service. He will be replaced by Mihaela van der Schaar from the University of California Davis. And Dennis Prather's area in physical optics will be taken over by Robert Magnusson of the University of Connecticut. I thank them both for their efforts and welcome their successors.

These new Associate Editors, along with their fellow board members, will be faced with a brand new way of operating this coming year. There will be a dramatic 
change in the submission and processing of manuscripts for Optical Engineering in the coming year. A new webbased manuscript management system called Peer X-Press, operated by the American Institute of Physics, will be brought online. It will affect not only the board but also our authors. This system will permit authors to submit and track their manuscripts from anywhere in the world via a standard Internet browser. It will allow reviewers to download papers and submit their reviews in the same manner. The Associate Editors and I will use it to manage the review and revision of papers. There will be more information forthcoming as we bring the system online. Currently the members of the Board of Editors are submitting dummy papers to test the system and work out the bugs. I will keep you posted on our progress. I'm sure it will be a major topic in next February's report.

Donald C. O'Shea Editor 